can be taken to prevent the recurrence of similar failure. The sub-committee does not consider that a review of this type, involving specialized technical knowledge of a number of different industries, combined with a particular appreciation of the facts affecting the position of Great Britain in the world economy, could be adequately carried out by any existing agency. While the proposed committee should take its evidence in secret, an early and informative report is regarded as essential, first as a means of bringing home to industry and the public the realities of the existing situation, and secondly, to afford a basis for settling the plan of action required to recover and maintain the industrial strength upon which our future as a nation depends.

\section{Newton and His Portraits}

Mr. F. E. Brasch, of the United States Library of Congress, has selected some of the best portraits of Newton for publication in Scripta Mathematica $(8,199 ; 1941)$. The earliest is by Sir Peter Lely, and is supposed to show Newton (who was born on Christmas Day, 1642, Old Style) as he appeared in 1665 (the year of the Great Plague), but there is grave doubt whether Newton sat for this. The first portrait that can be guaranteed authentic is by Sir Godfrey Kneller, and is dated 1689, two years after the publication of the "Principia". The other portraits all show Newton as president of the Royal Society, a position he held from 1703 until his death in 1727. One is by William Gandy (1706), four by Johann Vanderbank $(1720,1725,1726$ and 1726 again), and one by an unknown artist. There are also photographs of a bas-relief attributed to Wedgwood, of a bronze statue by the American sculptor C. E. Dallin (1897), and of the reconstruction in Wellesley, Mass., U.S.A. of the actual parlour from Newton's house in Leicester Fields, St. Martin's Street, London.

In another article (Science, 99, $437 ; 1944$ ), Mr. Brasch gives us some information about the influence of Newton on Russian science. For some unknown reason, Newtonian ideas were ignored in Russia long after they had been accepted in France, Germany and other countries. Indeed, it was not until quite recently that the formal recognition of his work became evident. His "Optics" was translated into Russian in 1927, and the "Principia" in 1936. However, the celebrations of the tercentenary of Newton's birth left nothing to be desired. They were on an impressive scale, much exceeding those in Great Britain, and culminated in the founding of fifteen Issac. Newton studentships.

\section{Texas Meteor Cloud}

Oscar E. Monnig has described the effects of a fireball observed on May 20 over Texas (Sky and Telescope, September). It travelled from west to east and left a meteor cloud; photographs, some of which are reproduced, were taken by different people. Unlike some fireballs, this one did not leave a persistent train; two minutes after Ray Dudley, in the middle of Pampa, had taken a photograph, he was able to secure another one which showed a great change, not only in the brilliance of the meteor oloud, but also in the amount of diffusion that had taken place. The sun had set 40 minutes in some places and 20 minutes in others when it was seen, and as it was visible for a radius of more than 300 miles, it must have been a very imposing object at first. Atmospheric resistance slowed down its speed, which was almost below that of incandescence 13 miles north-west of Pampa. Attempts to find fragments of the fireball, which almost certainly disintegrated (though there is no record of a report due to disintegration such as is often heard with fireballs) have so far been unsuccessful, but it is hoped that some of the debris will be obtained. A provisional path has been computed, and it appears that it became visible at a height of 56 miles, the dense cloud being formed at a height of 23 miles (this latter is considered very accurate), and its direction of flight was at an angle of about $45^{\circ}$ to the horizon.

\section{Insect Pest Resistance in Plants}

The Imperial Bureau of Plant Breeding and Genetics, Cambridge, has issued a Bibliography on Insect Pest Resistance in Plants (1s. 6d.). The sources drawn upon include publications from the British Commonwealth, the main European countries, the United States and various South American countries, the U.S.S.R. and Japan. In all, there are more than 550 references arranged according to subject, the chief of these being cereals, roots and tubers, cotton, sugar-cane, fruits and vegetables. Nematodes are dealt with in a special section. Many of the publications included have been abstracted in Plant Breeding Abstracts, and in many instances the original publications cited are available at the Bureau or in some co-operating library, and further information can therefore, if necessary, be obtained on application to the Bureau. It is believed that the bibliography will be of practical assistance not only to the breeder and the geneticist, but also to all who are interested in the solution of the important problem of the fundamental basis of insect or nematode resistance among crop plants.

\section{Poliomyelitis in Argentina}

The July issue of the Boletin de la Oficina Sanitaria Panamericana contains an instructive article by Dr. G. Bayley Bustamante, assistant professor of public health, Buenos Aires, dealing with the last outbreak of poliomyelitis in the Argentine (October 1942-May 1943 with 1,948 cases). This was probably the largest outbreak, although epidemics were reported in 1909 , $1911,1916-17,1919-20,1924-25,1932-33,1934-35$ and 1936, mostly in the Buenos Aires and Rosario Area, with smaller outbreaks and sporadic cases in the rest of the country; but paralytic cases figure in the statistics in 1941 . There were 355 cases (189 in the Province of Santa Fé), which was an increase on the usual yearly figures. The 1942 epidemic in the southern suburb of Buenos Aires then extended into the city and to the rest of the province, with the peak in November and December; it increased along the coast after January and moved northward. The incidence was highest in the Buenos Aires sector. Half the cases were in children aged $1-3$ and another 10 per cent in those less than 1 year. The death-rate ranged from $3 \cdot 5$ to $23-25$ per cent, usually being 10 per cent. Of the eight large Argentine epidemics, four began in February and one each in June, September, October and November. The 1942-43 epidemic had its peak in October-November (spring); the year had been characterized by a hard but short winter, an early warm spring and a very hot and dry summer. 